\title{
Research on the Removal of Total Nitrogen and Total Phosphorus by Improved Constructed Rapid Infiltration System
}

\author{
Aibin Kang, Lixuan Wang and Bin Zhang \\ Hebei Chemical and Pharmaceutical College, Shijiazhuang, 050026, China
}

\begin{abstract}
Pollutant removal was researched in this paper, by using the improved constructed rapid infiltration system which was added sponge iron and special media of corn cob, and by taking wastewater of student life in campus as an object of study. Test results show that: after adding additional carbon corncob, the removal rate of total nitrogen increases by nearly $50 \%$ than conventional systems, so the effect is obvious. Corn cob can not only provide the required carbon source, but also can serve as microbial attachment carrier, and it is good for microbial growth. After the addition of sponge iron, the removal of total phosphorus rate is $92 \%$, the average effluent concentration is $0.32 \mathrm{mg} / \mathrm{L}$, and the effluent can meet the $\mathrm{I}-$ A of " Discharge standard of pollutants for municipal wastewater treatment plant(GB 18918-2002). The sponge iron achieves phosphorus removal by adsorption and chemical reactions. The improved system can also ensure the removal of COD and ammonia.
\end{abstract}

Keywords-constructed rapid infiltration system; total nitrogen; total phosphorus; sponge; corn cob

\section{INTRODUCTION}

Constructed Rapid Infiltration System (CRI) is a new method of biological treatment, developed from the traditional land treatment system of wastewater. It has advantages of good treatment effect, low investment, easy management, simple operation, and low cost of operation [1]. It mainly used in the research of sewage, bathing water, micro-polluted water and other aspects in China recent years, and it had practical engineering application [2-5].

However, because the internal system of anaerobic environment was undesirability, the carbon was inadequate and environment of phosphorus removal was not suitable, the removal rate of $\mathrm{TN}$ and $\mathrm{TP}$ was low by using this technology, and could not meet the standards of relevant emission [6]. The experiment investigated the removal of total nitrogen and total phosphorus of this system by adding additional carbon and media of phosphorus removal.

\section{EXPERIMENTAL DESIGN}

\section{A. Quality of the Experimental Water}

The experimental water came from septic tanks of students' life district in campus, and waste water mainly came from washing, flushing and other miscellaneous water of students' dormitories. Raw water flowed from the septic tank into the conditioning tank, then after the micro-aeration, flowed into the service reservoir and used as reserved water. Here are the indexes of the experimental wastewater quality: COD is $382.3 \sim 794.8 \mathrm{mg} / \mathrm{L}$, ammonia nitrogen is $103.9 \sim$ $174.4 \mathrm{mg} / \mathrm{L}$, NO2 $-\mathrm{N}$ is $0 \sim 0.97 \mathrm{mg} / \mathrm{L}$, NO3 $-\mathrm{N}$ is $0 \sim$ $0.52 \mathrm{mg} / \mathrm{L}$, and TN is $119.9 \sim 175.3 \mathrm{mg} / \mathrm{L}$. It can clearly be seen that this wastewater is typical wastewater with high ammonia nitrogen. The raw water flows into rapid infiltration system after being micro-aerated.

\section{B. Parameters of Experimental Design}

The diameter of device in CRI was $200 \mathrm{~mm}$, made of PVC tubes, and $1 \mathrm{~m}$ of the lower part was zone of saturation. Medium sand was used as filler, and the diameter medium sand was chosen between 0.4 and $1.2 \mathrm{~mm}, \mathrm{~d} 10=0.25 \mathrm{~mm}$, $\mathrm{Cu}=3.12$. The total height of medium was $2 \mathrm{~m}$, and it was placed between $0.5 \mathrm{~m}$ and $1.0 \mathrm{~m}$ from top. The special medium, that was sponge iron, was added according to the ratio of 1:3. Corn cob, used as carbon source, was added between $0.4 \mathrm{~m}$ and $0.8 \mathrm{~m}$ from the bottom. The height of Protection was $0.4 \mathrm{~m}$, and overflow mouth was placed at 0.1 $\mathrm{m}$ from the top. Designed running hydraulic load was 1.0 $\mathrm{m} / \mathrm{d}$, hydraulic loading cycle was $4 \mathrm{~h}$, and the ratio of wet dry was 1:5.

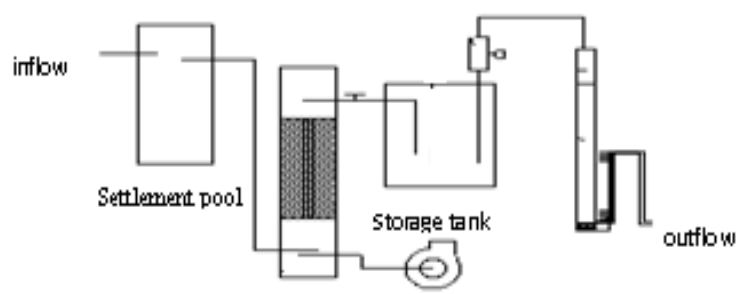

FIGURE I. DIAGRAM OF TREATMENT PROCESS.

\section{Sample Collection and Detecting Methods of Experiment}

The sample of experimental analysis were TN, TP, COD, NH4 - N, etc. And national standard method of China was adopted here. 


\section{RESULTS AND DISCUSSION}

\section{A. Removal Efficiency on Total Nitrogen}

The influent concentration of TN of was between 95 and $121 \mathrm{mg} / \mathrm{L}$ in normal operating stage, effluent concentration was between 19 and $33 \mathrm{mg} / \mathrm{L}$, the average effluent concentration was $25.6 \mathrm{mg} / \mathrm{L}$, and the average removal rate was $76.3 \%$. The effluent couldn't meet the I - B of " Discharge standard of pollutants for municipal wastewater treatment plant(GB 18918-2002) after the stability. The removal of total nitrogen in improved system was increased by $50 \%$ than conventional constructed rapid infiltration system [7]. The efficiency was obvious.

The lower part of the system used in this experiment was saturation layer with $1 \mathrm{~m}$ height. The anaerobic environment was added, and due to the adding of carbon source, the efficiency of denitrification was increased. The corn cod had certain hardness, so it could not only release the carbon source slowly, but also could act as attached carrier of microorganisms, and promote the denitrification at the same time. Although the removal efficiency of total nitrogen was obvious after adding carbon source, the final average concentration effluent was $25.6 \mathrm{mg} / \mathrm{L}$. Therefore, it still could not meet the limit of $20 \mathrm{mg} / \mathrm{L}$ in the the I - B of " Discharge standard of pollutants for municipal wastewater treatment plant(GB 18918-2002).

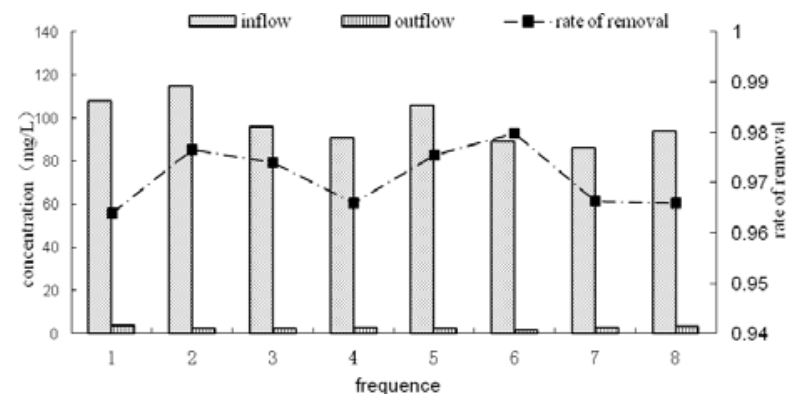

FIGURE II. THE RATE OF REMOVAL TOTAL NITROGEN.

The main reason was that the residence time was short. Hydraulic loading cycle was four hours in this experiment. While the height of the influent was raised, but the residence time was about 6 hours, it leading to the result that the total nitrogen in improved system could not meet the I - B of " Discharge standard of pollutants for municipal wastewater treatment plant(GB 18918-2002) standard ".
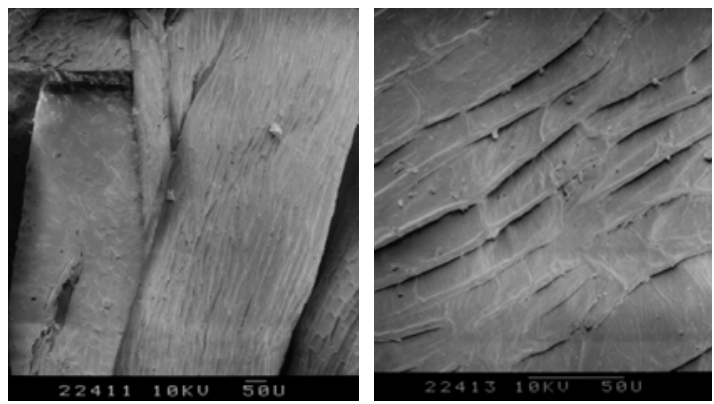

FIGURE III. BEFORE EXPERIMENT WITH SEM.
Half a year after Corn cob running as carbon source, the scanning electron microscopy (SEM) experiments were made.
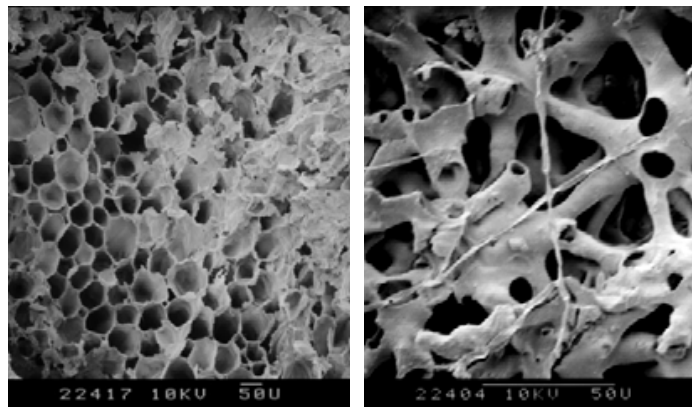

FIGURE IV. AFTER EXPERIMENT WITH SEM.

As shown in figure 3-4, the surface of corn cobs presented regular arrangement of strips. And there were cascading coverings on them, which were mainly lignin, cellulose, etc. After the experiment, due to the degradation of lignin, cellulose and carbohydrate, the structure of surface of corn cob had changed significantly, and had presented an irregular porous structure. The surface layer of coverings were degraded, and presented a regular arrangement of honeycomb. Along with the progress of experiment, it would be consumed and degraded slowly.

The existence of rod-shaped bacteria and staph can also be observed. Major of The main communities of denitrifying bacteria in the soil environment are bacillus genus, micrococcus and pseudomonas. Ma Ming-chao and other researchers used 16 SRNA technology to study the distribution of microbial communities in the middle and lower part of environment of conventional rapid infiltration system. Results showed that many kinds of denitrifying bacteria (Pseudomonas sp.) ,which were acid bacillus, purple color coli (Chromobasp.), raw silk micro bacteria genera (Hyphomicrobium sp) and Pseudomonas and [8] were found in clone library. These results tallied with the results of this experiment. In addition, after running of experiment more than half a year, the structure of the corn cod remained good, and had no obvious changes. This showed that corn cobs could not only provide needed carbon source, but also could be used as a carrier of microorganisms, and was more conducive to the growth of microorganisms.

\section{B. Removal Efficiency on Total Phosphorus}

The influent concentration of the total phosphorus was between 6.8 and $9.5 \mathrm{mg} / \mathrm{L}$ in normal operating system, the effluent concentration was between $0.210 .42 \mathrm{mg} / \mathrm{L}$, the average removal was $92 \%$, and the average effluent concentration was $0.32 \mathrm{mg} / \mathrm{L}$. The stable effluent could meet the I - A of " Discharge standard of pollutants for municipal wastewater treatment plant(GB 18918-2002) standard ". It proved that the improved system had very good effect of removal on total phosphorus. 


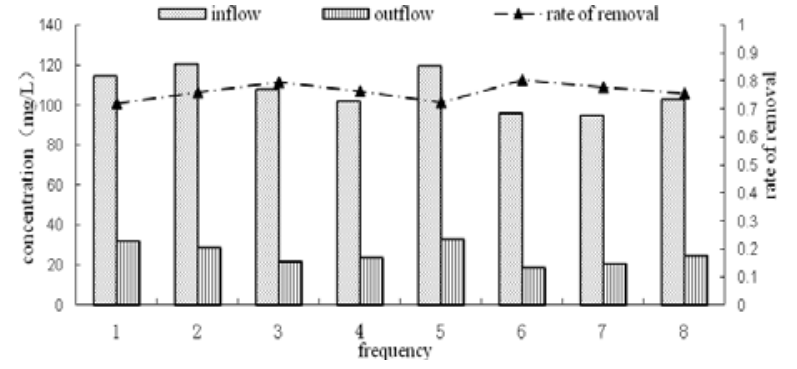

FIGURE V. THE RATE OF REMOVAL TOTAL PHOSPHORUS.

The sponge iron was added in improved system. Sponge iron is a metal porous structure, has a larger surface area, has a strong adsorption capacity of phosphorus, and it can generate $[\mathrm{H}]$ and $\mathrm{Fe} 2+$ in neutral or acidic environment in the meantime. Fe2 +further oxidized to $\mathrm{Fe} 3+$, and phosphate group and $\mathrm{Fe} 3$ +in wastewater could produce insoluble iron phosphate precipitate, thus being able to remove phosphorus. The results of scanning electron microscopy (SEM) are showed in figure 6. It is observed that the sponge iron presents decentralized structure before the experiment, and spaces are larger. The surface of sponge iron is surrounded by layers of membrane after experiment, and spaces becomes smaller. It further confirms that the removal of total phosphorus in the system is mainly dependent on the adsorption, retention and chemical action of percolation medium.
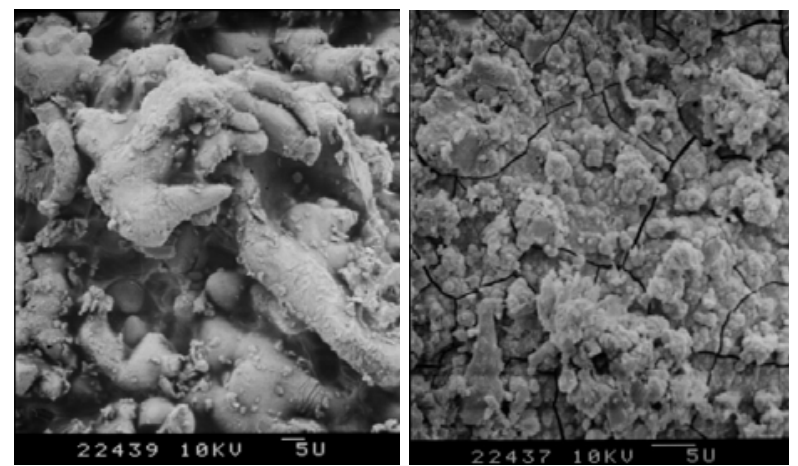

FIGURE VI. BEFORE AND AFTER EXPERIMENTS WITH SEM.

\section{Removal Efficiency on COD and Ammonia Nitrogen}

Influent concentration of COD in the improved system is between 176 and $260 \mathrm{mg} / \mathrm{L}$, average influent concentration is $32 \mathrm{mg} / \mathrm{L}$, and the average removal rate is $84.3 \%$. The effluent can meet the integrated urban sewage treatment plant pollutant discharge standard "(GB18918-2002) level of A standard. Influent concentration of $\mathrm{NH} 4-\mathrm{N}$ is between $86-108 \mathrm{mg} / \mathrm{L}$, average effluent concentration is $2.8 \mathrm{mg} / \mathrm{L}$, and the average removal rate is $97.1 \%$. The effluent can meet the I - A of " Discharge standard of pollutants for municipal wastewater treatment plant(GB 18918-2002) standard. It shows that the improved system could still guarantee removal effect of COD and ammonia nitrogen.

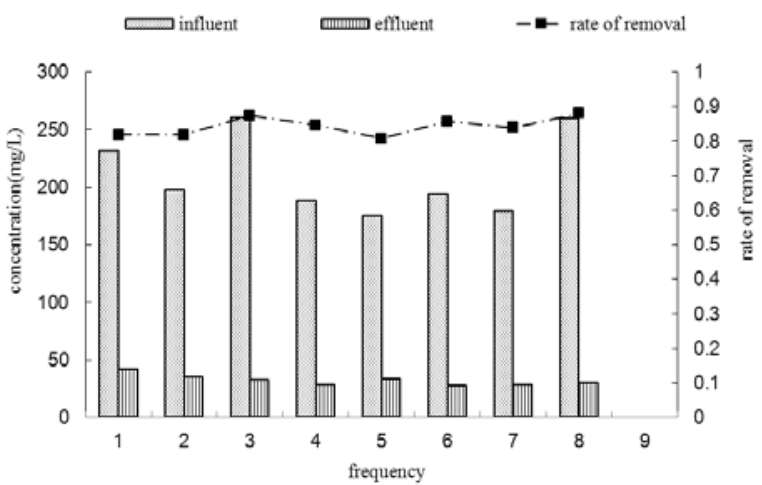

FIGURE VII. THE RATE OF REMOVAL COD.

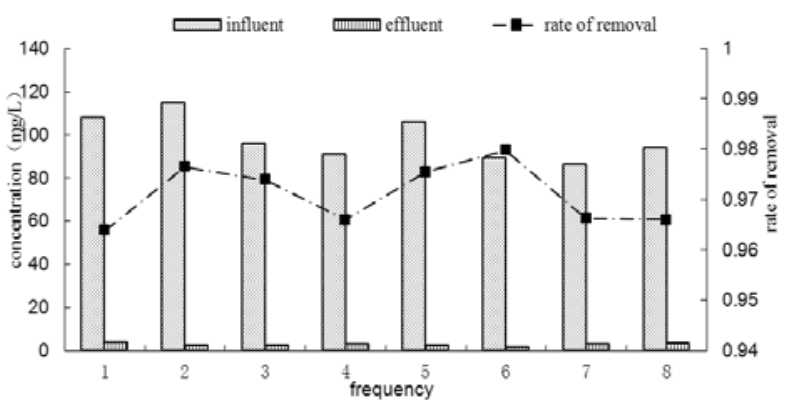

FIGURE VIII. THE RATE OF REMOVAL AMMONIA NITROGEN.

\section{CONCLUSION}

1) Removal rate of total nitrogen represents $50 \%$ increase from conventional system by adding the zone of saturation and corn cods. Promoting effect is obvious. Corn cobs can provide not only needed carbon source, also be used as a carrier of microorganism, and are more conducive to the growth of microorganisms.

2) Influent concentration of total phosphorus is between 6.8 and $9.5 \mathrm{mg} / \mathrm{L}$ after adding the sponge iron, the average removal rate is $92 \%$, the average effluent concentration is $0.32 \mathrm{mg} / \mathrm{L}$. the effluent could meet the I -A of " Discharge standard of pollutants for municipal wastewater treatment plant(GB 18918-2002) standard ".. Sponge iron reached effect of phosphorus removal through adsorption and chemical reaction.

3) Effluent concentration of COD and NH4 -n in the improved system can meet the I-A of " Discharge standard of pollutants for municipal wastewater treatment plant(GB 18918-2002) standard ". The improved system can guarantee the removal effect of COD and ammonia nitrogen.

\section{ACKNOWLEDGMENT}

This work was financially supported by the key technologies R \& D program of Hebei province (12273602). 


\section{REFERENCES}

[1] He Jiangtao, Zhong Zuoshen, Tang Minggao. Experimental research of constructed rapid infiltration wastewater treating system.China Environmental Science, 2002, 22 (3): 239-243.

[2] MU Xinmin et al . A On-site experimental study on the treatment of Mao Zhou River water by constructed rapid infiltration system in Shen Zhen[J]. JOURNAL OF BASIC SCIENCE AND ENGINEERING, 2003, 11 (4) :370- 377.

[3] ZHANG Jinbin ,HUANG Peihong et al. Constructed rapid infiltration system for treating domestic wastewater in DONGGUAN electrical equipment factory[J]. ENVIRONMENTAL ENGINEERING, 2003, 21 (6) : 32- 35

[4] KANG Aibin,YANG Yawen, WANG Shouwei et al. The treatment of livestock wastewater by three step series constructed rapid infiltration system[J]. CHINESE JOURNAL OF ENVIRONMENTAL ENGINEERING, 2009, 3(3):475-478.

[5] CUI Chengying,MA Limin,ZHANG Xuanjun et al. Mechanism of contamination removal in constructed rapid infiltration system[J]..ENVIRONMENTAL POLLUTION\&CONTROL， 2007, 29(2): 95-98

[6] GUO Jinsong ,WANG Chunyan ,FANG Fang, YIN Liang ,YAO Ruoxu.Applicability Study of CRI Treating Sewage in the ThreeGorges Reservoir Region[J]. ENVIRONMENTAL SCIENCE, 2006.27(11):.2327-2332.

[7] Ming-chao, JIANG Xin, LI Jun, HE Jiangtao.Analysis of nitrifying bacteria community denitrogenation action in constructed rapid infiltrition system. MA. China Environmental Science, 2008,28(4):350 354

[8] JIANG Xin,MA MingChao,LI Jun,LI,Li,ZHONG Zuo-Shen.Analysis of Microbial Community Distribution in Constructed Rapid Infiltrition System(CRI) by DGGE. Microbiology, 2007, 34(6): 11791183. 